DOI 10.37882/2500-3682.2020.10.11

\title{
ПЕРВИЧНАЯ ПСИХОЛОГО-ПЕДАГОГИЧЕСКАЯ ПРОФИЛАКТИКА АДДИКТИВНОГО ПОВЕДЕНИЯ ПОДРОСТКОВ: ПРОБЛЕМЫ, ПЕРСПЕКТИВЫ ИХ РЕШЕНИЙ
}

\section{PRIMARY PSYCHOLOGICAL AND PEDAGOGICAL PREVENTION OF ADDICTIVE BEHAVIOR OF ADOLESCENTS: PROBLEMS, PROSPECTS FOR THEIR SOLUTIONS}

S. Mast

Summary: The article presents the results of a study aimed at identifying current problems of primary psychological and pedagogical prevention of addictive behavior of adolescents and determining the prospects for their solutions in the context of recent scientific ideas. The relevance of the study is due to the crisis in the development and formation of personality in adolescence, due to the possibility of choosing an addictive behavior strategy by a teenager and the need to carry out a set of measures aimed at preventing it. The author presents the primary prevention program «New way!», which aims to form protective coping resources and productive coping strategies in adolescents. Thanks to the conceptual basis, clarity and realism in the formulation of the program's objectives, a significant strengthening of protective and adaptive factors is achieved, thereby reducing the actions of risk factors, and contributing to the development of personal.

Keywords: adolescent, addictive behavior, primary psychological and pedagogical prevention, protective coping resources, productive coping strategies.

\author{
Маст Светлана Викторовна \\ Аспирант, ГАОУ ВО Ленинградской области \\ «Ленинградский государственный университет \\ имени А.С. Пушкина» \\ Svetlanamast@mail.ru
}

Аннотация: В статье представлены результаты исследования, целью которого стало выявление современных проблем первичной психолого-педагогической профилактики аддиктивного поведения подростков, и определение перспектив их решений в контексте последних научных представлений. Актуальность исследования обусловлена кризисностью в развитии и становлении личности в подростковый период, возможностью выбора подростком аддиктивной стратегии поведения и необходимостью проведения совокупности мероприятий, направленных на ее предупреждение. Автором представлена программа первичной профилактики «Новый путь!», целью которой является формирование протективных копинг-ресурсов и продуктивных копинг-стратегий подростка. Благодаря концептуальной основе, четкости и реалистичности в постановке задач программы достигается существенное усиление протективных и адаптационных факторов, тем самым уменьшая действия со стороны факторов риска, и содействуя развитию ресурсов личности.

Ключевые слова: подросток, аддиктивное поведение, первичная психологопедагогическая профилактика, протективные копинг-ресурсы, продуктивные копинг-стратегии.

\section{Введение}

$\Pi$ рофилактика аддиктивного поведения приобретает особую значимость в подростковом возрасте, который является кризисным в развитии и становлении личности. Именно этот период характеризуется формированием важных, с точки зрения личностного развития подростка, качеств, среди которых стремление к развитию и к саморазвитию, интерес к своей личности и ее потенциалам через самонаблюдение, что в целом может служить основанием для предположения об их рассмотрении в качестве объекта для воздействия в ходе профилактики аддикции.

\section{Теоретический анализ проблемы исслеАования}

Одним из центральных личностных новообразований подросткового периода следует считать становле- ние самосознания, Я-концепции, которое находит своё отражение в стремлении понять себя, определить свои возможности и выявить превалирующие особенности, что можно рассматривать в качестве своеобразной сатисфакции своей уникальности и неповторимости. Как психологическое условие аддиктивного поведения подростков представлен комплекс психологических характеристик, включающий в себя эгоцентрическую направленность и низкий уровень рефлексии.

Л.С. Выготский (1984) считал, что «именно в подростковом возрасте влияние среды на развитие мышления приобретает особую значимость», «в подростковом возрасте механизмы преодоления стресса носят динамический и транзиторный характер, обеспечивают развитие индивида, способствуют или препятствуют включению биологических и социальных факторов риска поведенческих, психосоматических и психических нарушений». 
Ряд отечественных исследователей считают, что во многих случаях аддиктивное поведение подростков обусловлено действием механизмов поиска новых впечатлений на фоне неразвитости у них сферы потребностей, искажения процесса социализации и особенностей эмоциональной сферы: низкой стрессоустойчивости, повышенной тревожности, импульсивности (Пригожин И. 2003, стр. 34-35). В подростковом возрасте сильные эмоции возникают чаще по сравнению со взрослыми, что вызывает своеобразную «блокировку» в принятии разумных решений (Божович Л.И. 1997, стр. 187).

Механизмы преодоления стресса необходимы в жизни подростков в кризисные ситуации. Семья («ссоры в семье»), взаимоотношения со сверстниками («конфликт с другом»), взаимоотношения со значимым взрослым («конфликт с учителем»), учебная деятельность, здоровье («болезни, травмы») - типичные кризисные ситуации по мнению отечественных ученых.

С позиции научных психологических и педагогических теории в качестве определяющих факторов риска, способных вызывать аддиктивное поведение в подростковом возрасте следует рассматривать микросредовые факторы, обуславливающие особенности взаимоотношений подростков со взрослыми и сверстниками.

Социальная поддержка в этот период играет важную роль. Сказанное определяется особенностями подросткового возраста, характеризуемого интенсивностью процессов обучения, в ходе чего происходит освоение способов психологического преодоления жизненных трудностей. В этот период успешность становления личности подростка определяется уровнем его взаимодействия в совместной деятельности со взрослым. Следует отметить некоторое противоречие, проявляемое у подростков, которое выражается в стремлении противопоставить себя взрослым, в ходе демонстрации своей независимости, при этом ожидая от них психологической поддержки.

Адекватные формы, наиболее часто позиционируемые как «взрослость» (ответственность, социальная активность, открытое проявление собственной точки зрения и т.д.), в подростковом возрасте формируются при непосредственной поддержки со стороны взрослых. Проявление своих возможностей в ходе выявления своих сильных и слабых сторон, самостоятельном определении причины удач и неудач подростком, возможно благодаря поддержки и помощи взрослых.

Кроме отмеченного, следует подчеркнуть значимость еще одного важного фактора, способного существенно отразиться на психическом развитии подростка - общение со сверстниками. В подростковом возрасте важным является реализация психологических потребностей посредством общения со сверстниками, в которых подросток стремиться продемонстрировать свою самостоятельность и независимость. В контексте сказанного в условиях реализации межличностных отношений важной составляющей выступает эмоциональная насыщенная, что обусловлено значимостью его признания (Жарикова Т.П. 2011).

Недостаток эмоционального общения, в том числе и в семье, побуждает в них желание поиска искусственно вызванных положительных эмоций, недостаток которых подросток ощущает в реальной жизни. Встречаемые на пути жизненного становления подростком трудности, определяют необходимость разработки конкретных стратегий с целью их преодоления, которые могут рассматриваться в качестве его ответной реакции на требования со стороны окружающей его среды.

В подростковом возрасте существует возможность реализации одной из множества потенциальных альтернатив развития, которые могут быть как позитивными, так и негативными. Позитивный результат решения возрастных задач способствует переходу на более высокую ступень развития (Л.С. Выготский (1984), интеграцию свободы и ответственности в единый механизм автономной детерминации зрелой личности (Д.А. Леонтьев с.79), формированию идентичности (Э. Эриксон с.165).

Множество новых противоречивых жизненных ситуаций, неизбежных для возрастного кризиса, недостаток личностного ресурса для разрешения психологических проблем повышают вероятность выбора аддиктивной стратегии поведения.

Теория копинг-поведения, выделенная нами в качестве теоретической основы психолого-педагогической профилактики аддиктивного поведения подростков, предполагает выстраивание особой системы профилактики.

В широком смысле термин профилактика означает «совокупность мероприятий, направленных на предупреждение каких- либо нежелательных явлений» (Змановская Е.В. 2003). Исследователи, используя термин профилактика как совокупность государственных, общественных, социально-медицинских и организационно-воспитательных мероприятий, направленных на предупреждение, устранение или нейтрализацию основных причин и условий, вызывающих различного рода социальные отклонения в поведении подростков, нередко заменяют его термином превенция (от лат. preventus-предупреждать что-либо), что обозначает комплекс действий, предупреждающих опасное развитие событий, принимают эти понятия как синонимы, и 
употребляют их равноправно (Музаева Ю.А. 2007. С. 62).

Общепринятым является классификация профилактических мероприятий на первичные, вторичные и третичные. В частности, Всемирная организация здравоохранения (далее $\triangle \mathrm{BO}$ ) следующим образом определяет перечисленные уровни профилактических мер: первичная профилактика преследует цель устранение неблагоприятных факторов, способных вызвать повышение уровня устойчивости личности и возможности её противодействия внешним факторам; целью вторичной профилактики является выявление конкретных нарушений и деятельность с подростками, относимыми к так называемой «группе риска»; третичная профилактика нацелена на решение специальных задач, в частности, лечение, коррекция нарушений, предупреждение их рецидивов и реабилитация «травмированных» функций [Змановская Е.В. 2003.].

До настоящего времени, представления о значимости первичной профилактики, первоначально представленной в виде системы наказаний, запретов и санитарного просвещения (Личко А.Е., Битенский В.С., 1991), постоянно видоизменялись, что обусловлено неоднозначностью исследуемой деятельности.

\section{Хом и результаты исслеАования}

На протяжении многих лет первичная профилактика была представлена в виде информирования населения о состоянии проблемы, с раскрытием тяжести медицинских и социальных последствий разнообразных зависимостей, исключая нехимические её виды (Егоров А.Ю. 2007.). Однако, согласно справедливому с нашей точки зрения мнению, высказанному Б. Спрангером (1994), трансляцию информации не следует рассматривать в качестве процесса обучения, в то время как информационный подход реализуется до настоящего момента в качестве основного при реализации разнообразных профилактических программ, не решающих проблем поведения подростка.

На первый план выходят вопросы психолого-педагогической профилактики аддиктивного поведения у подростков, содействие становлению личности и ее самореализации. В свете сказанного, профилактические мероприятия, ориентированные на пропедевтику аддиктивного поведения подростков, выступает в качестве основной цели первичной профилактики. В решении проблем аддиктивного поведения предпочтение отдается первичной психолого-педагогической профилактике (Симатова О.Б. 2008).

Как определяющая составляющая системы первичной профилактики аддиктивного поведения детей-си- рот и детей, оставшихся без попечения родителей с целью формирования протективных копинг-ресурсов и продуктивных копинг-стратегий, на базе Бюджетного учреждения Ханты-Мансийского автономного округаЮгры «Центр помощи детям, оставшимся без попечения родителей, «Аистенок» была разработана и реализована программы первичной профилактики аддиктивного поведения подростков, проживающих в замещающих семьях, «Новый путь!».

Для реализации поставленной цели решались следующие задачи программы:

1. Развитие когнитивного, эмоционального и поведенческого компонентов копинг-поведения и когнитивно-оценочных механизмов подростков;

2. Развитие личностных ресурсов подростков, способствующих формированию здорового жизненного стиля и высокоэффективного поведения (адекватная самооценка, Я-концепция, эмпатия, аффилиация, стремление к успеху и др.).

3. Формирование навыков эффективного взаимодействия в семье, совершенствование функций семьи, которые способствуют развитию здоровой личности, через развитие личностных ресурсов родителей, повышение родительских компетенций.

4. Развитие кадровых и общественных ресурсов для работы по профилактике аддиктивного поведения подростков, проживающих в замещающих семьях.

5. Распространение эффективных форм и методов работы с целевыми группами.

В соответствии с целью и поставленными задачами, были определены ожидаемые конечные результаты реализации Программы:

1. Повышение эффрективности системы по реализачии комплекса мер, направленных на профилактику аддиктивного поведения подростков, проживающих в замещающих семьях:

- актуализация знаний специалистов по современным подходам к профилактике аддиктивного поведения подростков;

- повышение мотивации специалистов к деятельности, обучение навыкам и приемам саморегуляции, управления конфликтом, управления стрессом и др.;

- обеспечение личностно-профессионального, культурного, творческого роста специалистов; совершенствование профессиональных компетенций;

- повышение эффективности профилактики аддиктивного поведения несовершеннолетних;

- повышение эффективности работы с семьями (замещающими родителями). 
1. Повышение эффективности системы по реализации комплекса мер, направленных на профилактику аддиктивного поведения подростков, проживающих в замещающих семьях.

Задача 1. Развитие кадровых и общественных ресурсов для работы по профилактике аддиктивного поведения подростков, проживающих в замещающих семьях.

\begin{tabular}{|c|c|c|}
\hline 1.1. & $\begin{array}{l}\text { Организация взаимодействия с субъектами профилактики и иными } \\
\text { структурами по реализации Программы. }\end{array}$ & $\begin{array}{l}\text { Количество субъектов профилактики } \\
\text { Количество человек }\end{array}$ \\
\hline 1.2. & $\begin{array}{l}\text { Актуализация знаний по современным подходам к профилактике ад- } \\
\text { диктивного поведения подростков. }\end{array}$ & Количество человек \\
\hline 1.3. & Повышение квалификации специалистов. & Количество человек \\
\hline 1.4. & $\begin{array}{l}\text { Повышение мотивации специалистов к деятельности, обучение навы- } \\
\text { кам и приемам саморегуляции, управления конфликтом, управления } \\
\text { стрессом и др. }\end{array}$ & $\begin{array}{l}\text { Количество мероприятий } \\
\text { Количество человек }\end{array}$ \\
\hline 1.5 . & $\begin{array}{l}\text { Обеспечение личностно-профессионального, культурного, творческо- } \\
\text { го роста специалистов; Совершенствование профессиональных компе- } \\
\text { тенций; Освоение нового содержания и технологий психолого-педаго- } \\
\text { гической деятельности }\end{array}$ & $\begin{array}{l}\text { Количество мероприятий } \\
\text { Количество человек }\end{array}$ \\
\hline 1.7. & $\begin{array}{l}\text { Обмен профессиональным опытом, } \\
\text { информацией; обретение и поддержка профессиональной идентич- } \\
\text { ности; } \\
\text { возможность получить поддержку коллег; } \\
\text { обретение альтернативных способов действий в работе с клиентом; } \\
\text { разбор сложных случаев. }\end{array}$ & $\begin{array}{l}\text { Количество человек } \\
\text { Количество встреч }\end{array}$ \\
\hline 1.8. & Удовлетворённость специалистов участием в программе & \% от общего количество специалистов \\
\hline 1.9. & $\begin{array}{l}\text { Подведение итогов реализации Программы, обобщение полученных } \\
\text { результатов, определение перспективных планов по сохранению полу- } \\
\text { ченных результатов }\end{array}$ & $\begin{array}{l}\text { Количество человек } \\
\text { Количество субъектов }\end{array}$ \\
\hline
\end{tabular}

Задача 2. Распространение эффективных форм и методов работы с подростками, склонными к аддиктивному поведению, проживающими в замещающих семьях, с замещающими родителями

\begin{tabular}{|l|l|l|}
\hline 2.2. & 0бобщение материалов в рамках реализации Программы. & $\begin{array}{l}\text { Количество экземпляров } \\
\text { сборника методических материалов }\end{array}$ \\
\hline 2.3. & $\begin{array}{l}\text { Повышение эффективности профилактики аддиктивного поведения } \\
\text { несовершеннолетних }\end{array}$ & Количество рекомендаций. Количество экземпляров \\
\hline 2.4. & $\begin{array}{l}\text { Повышение эффективности работы с } \\
\text { семьями (замещающими родителями). }\end{array}$ & $\begin{array}{l}\text { Количество брошюр. Количество экземпляров } \\
\text { Издичество публикаций }\end{array}$ \\
\hline 2.5. & Информирование о ходе и результатах реализации Программы. \\
\hline
\end{tabular}

2. Формирование протективных копинг-ресурсов и продуктивных копинг-стратегий поведения подростков через организацию превентивной деятельности всех участников процесса;

Задача 1. Развитие когнитивного, эмоционального и поведенческого компонентов копинг-поведения и когнитивно-оценочных механизмов; Задача 2. Развитие личностных ресурсов подростков, способствующих формированию здорового жизненного стиля и высокоэффективного поведения (адекватная самооценка, Я-концепция, эмпатия, аффилиация, стремление к успеху и др.).

\begin{tabular}{|l|l|l|}
\hline 3.1. & $\begin{array}{l}\text { Формирование здорового жизненного стиля и высокоэффективных } \\
\text { поведенческих стратегий подростков. }\end{array}$ & Число подростков, выбирающих продуктивные копинг-стратегии \\
\hline 3.2. & Развитие личностных ресурсов подростков. & $\begin{array}{l}\text { Число подростков, имеющих адекватную самооценку } \\
\text { Число подростков с адекватным уровнем тревожности } \\
\text { Число подростков со средними и высокими показателями уровня эм- } \\
\text { патии } \\
\end{array}$ \\
& $\begin{array}{l}\text { Число подростков, имеющих позитивную мотивацию на успех } \\
\text { Количество тренингов }\end{array}$ \\
\hline
\end{tabular}




\begin{tabular}{|l|l|l|}
\hline № п/п & \multicolumn{1}{|c|}{ Целевой показатель } & \multicolumn{1}{|c|}{ Индикатор } \\
\hline 3.3. & $\begin{array}{l}\text { Развитие стратегий и навыков поведения, ведущих к здоровью и пре- } \\
\text { пятствующих поведению риска, использование альтернативных спосо- } \\
\text { бов получения радости и удовольствия, } \\
\text { позитивного общения }\end{array}$ & $\begin{array}{l}\text { Количество участников } \\
\text { Количество мероприятий } \\
\text { 0бщий охват участников, в том числе принимающих участие в различ- } \\
\text { ных мероприятиях }\end{array}$ \\
\hline 3.4. & $\begin{array}{l}\text { Повышение информированности подростков о действии и послед- } \\
\text { ствиях употребления психоактивных веществ }\end{array}$ & $\begin{array}{l}\text { Количество участников } \\
\text { Количество мероприятий }\end{array}$ \\
\hline 3.5. & Удовлетворённость подростков участием в программе & \% от общего количества подростков \\
\hline 3. Оказание психолого-педагогической поддержки семьям, воспитывающим подростков, склонных каддиктивному поведению.
\end{tabular}

- межведомственная интеграция образовательных учреждений, БУ ЦПД «Аистенок», субъектов профилактики и иных структур в рамках реализации Программы;

2. Формирование протективных копинг-ресурсов и продуктивных копинг-стратегий поведения подростков через организацию превентивной деятельности всех участников прочесса:

- формирование здорового жизненного стиля и высокоэффективных поведенческих стратегий подростков;

- развитие личностных ресурсов подростков;

- развитие стратегий и навыков поведения, ведущих к здоровью и препятствующих поведению риска, использование альтернативных способов получения радости и удовольствия, позитивного общения;

- повышение информированности подростков о действии и последствиях употребления психоактивных веществ.

3. Оказание психолого-педагогической поддержки семьям, воспитывающим подростков, склонных к аддиктивному поведению:

- повышение уровня знаний родителей, формирование семейного проблем-преодолевающего поведения;

- развитие личностных ресурсов родителей, родительских компетенций, повышение эффективности взаимодействия в семье, развитие навыков позитивного взаимодействия с подростками.
Были определены целевые показатели и индикаторы программы.

\section{Выводы}

Стратегическим приоритетом первичной психологопедагогической профилактики аддиктивного поведения подростков являлось создание системы позитивной профилактики, в центре которой находится личность подростка, а основная задача состояла в реализации его личностных копинг-ресурсов. Включение подпрограмм для родителей, и мероприятий по подготовке специалистов, привлечение к участию в реализации программы общественных ресурсов способствует развитию социальной среды. Работа с родителями направлена на повышение родительских психолого-педагогических компетенций, что содействует уменьшению факторов риска зависимого поведения, связанных с семьей. Развитие кадровых и общественных ресурсов для работы по профилактике аддиктивного поведения подростков, проживающих в замещающих семьях, позволит привлечь общественное внимания к проблеме, даст возможность дальнейшего распространения эффективных форм и методов работы с целевыми группами.

Наличие концептуальной основы, четкость и реалистичность в постановке цели и задач программы, направленность на усиление протективных и адаптационных факторов и уменьшение факторов риска, развитие ресурсов личности обеспечивают ее адекватность современным направлениям профилактики. 


\section{ЛИТЕРАТУРА}

1. Божович Л.И. Проблемы формирования личности: избранные психологические труды / Под ред. Д.И. Фельдштейна. - М.: Издательство «Институт практической психологии». Воронеж: НПО «МОДЭК», 1997. - 352 с.

2. Выготский Л.С. Собрание сочинений: В 6 т. Т. 4. Детская психология /Под ред. Д.Б. Эльконина.-М.: Педагогика, 1984. - 432 с.

3. Егоров А.Ю., Игумнов С.А. Расстройства поведения у подростков: клинико-психологические аспекты. - СПб.: Речь, 2005. - 436 с.

4. Жарикова Т.П. Психологические особенности ресурсного подхода к психолого-педагогической профилактике факторов риска аддиктивного поведения в подростковом возрасте: дис... канд. псих. наук, Самара 2011. - 183 с.

5. Змановская Е.В. Девиантология: психология отклоняющегося поведения личности: Учеб пособие для студ. высш. учеб. заведений. - М.: Академия, 2003. -288 C.

6. Леонтьев Д.А. Личностный потенциал как потенциал саморегуляции //Ученые записки кафедры общей психологии МГУ им. М.В. Ломоносова/ Под ред. Б.С. Братуся, Е.Е. Соколовой.-М.: Смысл, 2006. Вып. 2. -с. 85-105.

7. Личко А.Е. Подростковая наркология / А.Е. Личко, В.С. Битенский - Л.: Медицина, 1991. - 304 с. 17. Казанская-В.Г.-Подросток,- Трудности взросления: -книга для психологов, педагогов, родителей. - СПб.: Питер, 2006. - 240 с.

8. Музаева Ю.А. Минимизация проблемных полей в педагогической профилактике девиантного поведения детей-сирот в детском доме: дис. . . канд. пед. наук / Музаева Ю.А. - Омск, 2007.

9. Пригожин И. Порядок и хаос: Новый диалог человека с природой/И. Пригожин, И. Стенгерс. - М.: УРСС, 2003. -310 с.

10. Симатова, 0.Б. Первичная психолого-педагогическая профилактика аддиктивного поведения подростков в условиях средней общеобразовательной школы: дис... канд. псих. наук / 0.Б. Симатова - Иркутск, 2008. - 213 с.

11. Спрангер Б.Е. Анализ состояния обучающих программ “Формирование жизненных навыков” в мире// Вопросы наркологии. -1994.-№1.

12. Эриксон Э. Детство и общество: Пер. с англ. /ред. А.А. Алексеев. -2-е изд., перераб. и доп. - СПб.: Речь, 2000. -416 с.

13. Brown R.I. F. Some contributions of the study of gambling to the study of other addictions // In W.R.Eadingtone \& J.A.Cornclius. Gambling Behavior and Problem Gambling. Reno: University of Nevada Press. 1993. P.241- 272.

14. Lazarus R.S. Psychological-stress-and coping-process. - New-York McGraw Hill. - 1966.

15. Miller W. Addictive behaviors: Treatment of alcoholism, drug, abuse, smoking and obesity. Oxford etc: Pergamon Press, 1984. - 353 p.

(c) Маст Светлана Викторовна (Svetlanamast@mail.ru).

Журнал «Современная наука: актуальные проблемы теории и практики»

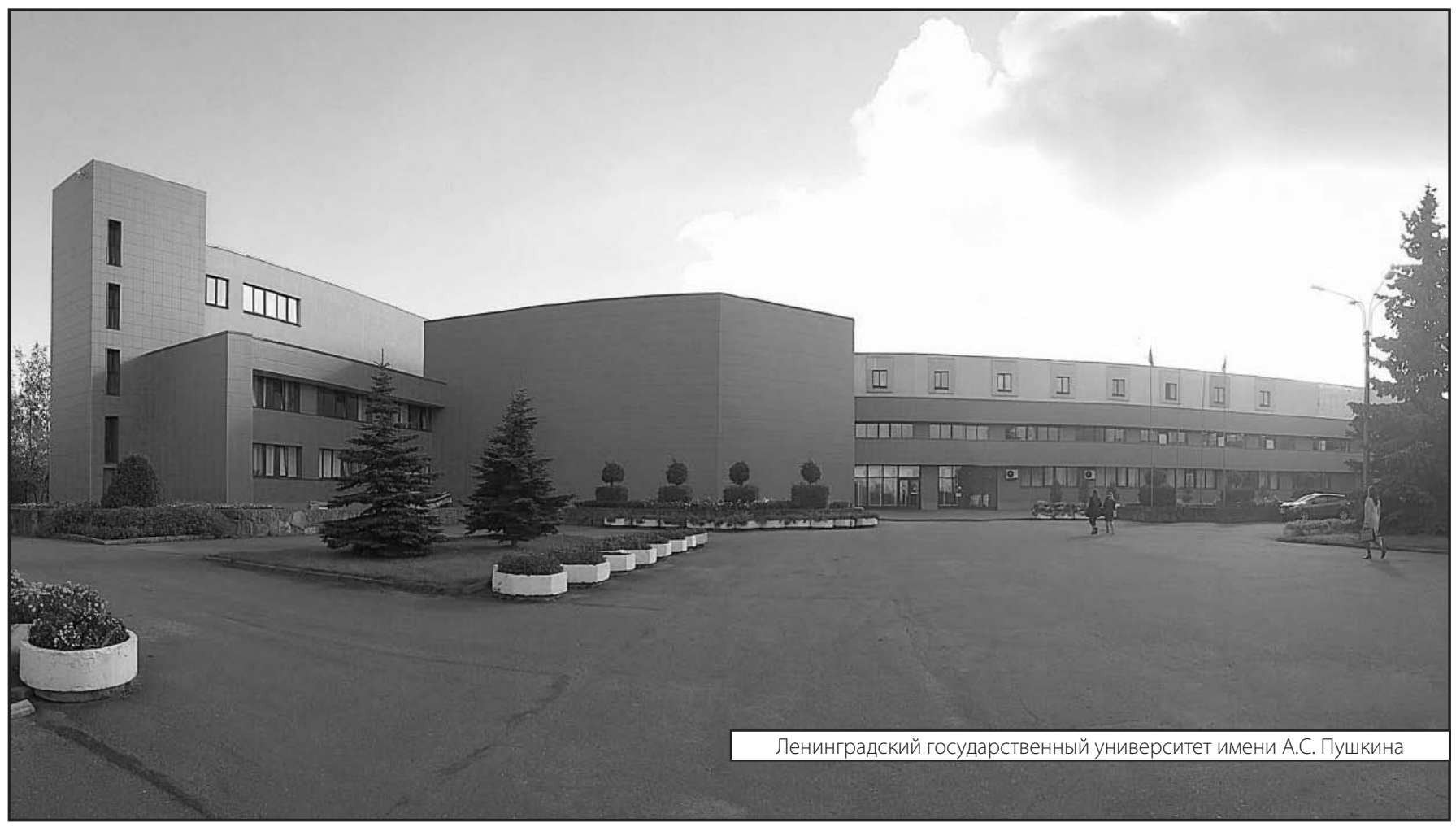

